\title{
A seeded ambient temperature ferrite process for treatment of AMD waters: Magnetite formation in the presence and absence of calcium ions under steady state operation
}

\author{
Morgan $\mathrm{BE}^{1 *}$, Lahav $\mathrm{O}^{2}$, Hearne $\mathrm{GR}^{3}$ and Loewenthal $\mathrm{RE}^{1}$ \\ ${ }^{1 *}$ Department of Civil Engineering, University of Cape Town, Rondebosch 7701, South Africa \\ 2 Faculty of Civil Engineering, Technion - Israel Institute of Technology, Haifa, 32000, Israel \\ 3 School of Physics, University of the Witwatersrand, Private Bag 3, WITS 2050, Johannesburg, South Africa
}

\begin{abstract}
An ambient temperature ferrite process has been developed for the removal of iron and non-ferrous metals from AMD waters. The process involves the controlled formation of magnetite $\left(\mathrm{Fe}_{3} \mathrm{O}_{4}\right)$ that has the capacity to substitute divalent and trivalent cations as part of the lattice, thus forming a stable easy-to-separate ferrite. This paper reports on continuous operations of the process in the absence and presence of $\mathrm{Ca}^{2+}$, which is well known to impede ferrite formation. In the first instance, the process involves the precipitation of hydroxy-metals at $\mathrm{pH} 10.5$ and their subsequent adsorption onto magnetite seed in a contact stabilisation reactor. Second, liquid-solid separation is effected and the solid fraction is subsequently treated in an oxidising reactor in which a fraction of the ferrous species is oxidised to an intermediate ferric precipitate. Finally, both ferrous and ferric species undergo crystalchemical processing and are incorporated into stable magnetite. Results indicate that $\mathrm{Ca}^{2+}$ interference can be overcome by maintaining a high ratio of precipitated ferrous species to dissolved $\mathrm{Ca}^{2+}$. It was found that in order to attain the required high $\mathrm{Fe}^{2+}: \mathrm{Ca}^{2+}$ ratio, the solid ferrous-hydroxy species concentration in the oxidation reactor should be maintained at above $1200 \mathrm{mg}$ $\mathrm{Fe} / \mathrm{l}$. Ferrous to calcium ratios greater than 3 were found to favour magnetite formation. In the absence of $\mathrm{Ca}^{2+}$, a solid ferroushydroxy species concentration of approximately $500 \mathrm{mg} / \mathrm{l}$ was sufficient for magnetite formation. Operating the process at ferroushydroxy concentrations of lower than 1200 and $500 \mathrm{mg} / \mathrm{l}$ in the presence and absence of calcium respectively enhanced the formation of other iron oxides, primarily goethite. In all experiments the iron concentration in the effluent was less than $1 \mathrm{mg} / \mathrm{l}$, the sludge volume index (SVI) extremely low $(<4 \mathrm{ml} / \mathrm{g}$ ) and the percentage of ferrous-hydroxy species in the sludge can be reduced to about $1 \%$. These features, together with the potential to incorporate heavy metals into a stable compound, make the process very promising for AMD treatment.
\end{abstract}

Keywords: ferrite process, magnetite seed, calcium interference, acid mine drainage.

\section{Introduction}

Acid mine drainage (AMD) arises from the oxidation of iron pyrite according to Eq. (1). In addition to dissolved sulphate, ferrous iron and acidity, the resulting water contains a variety of dissolved nonferrous metals. The type and concentration of these metals vary with the local geology.

$$
\begin{gathered}
\mathrm{O}_{2} \text {, Bacteria } \\
\mathrm{FeS}_{2}+14 \mathrm{Fe}^{3+}+8 \mathrm{H}_{2} \mathrm{O} \rightarrow 15 \mathrm{Fe}^{2+}+2 \mathrm{SO}_{4}^{2-}+16 \mathrm{H}^{+}
\end{gathered}
$$

The common approach to the removal of dissolved metals from AMD is to oxidise the ferrous iron to ferric oxides/oxo-hydroxides, which then precipitate and settle. The products of iron oxidation may vary from amorphous non-crystalline ferrihydrite $\left(\mathrm{Fe}(\mathrm{OH})_{3}\right)$ to crystalline ferric oxides/oxy-hydroxides such as $\mathrm{FeOOH}, \mathrm{Fe}_{2} \mathrm{O}_{3}$, or the partially oxidised ferrous-ferric crystalline compound magnetite $\mathrm{Fe}_{3} \mathrm{O}_{4}$. In general, the precise end-products of oxidation of ferrous solutions depend upon environmental conditions such as

\footnotetext{
* To whom all correspondence should be addressed.

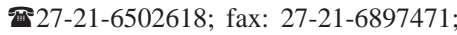

e-mail: mrgbar003@mail.uct.ac.za

Received 18 November 2002; accepted in revised form 29 January 2003.
}

$\mathrm{pH}$, redox potential, temperature, concentration of reagents, presence of seed, etc. (Blesa and Matijevic, 1989; Cornell and Schwertmann, 1996). Characterisation and quantification of individual components are complex and often impossible.

There are three criteria which the sludge of an AMD metals removal treatment process should meet:

- Efficient settling.

- Rapid and extensive dewatering properties in order to achieve a high density at the time of disposal.

- Stability of the sludge at low $\mathrm{pH}$, to avoid possible remobilisation of dissolved metals in the environment at the disposal site.

Crystallised end-products settle and dewater more efficiently than the poorly-crystalline/amorphous ferrihydrite does. In the event of a fall in $\mathrm{pH}$, ferrous and non-ferrous metal release from crystallised end-products is also less than for amorphous products of oxidation. Achievement of crystallised end-products is, however, not straightforward. In the currently deployed high-density sludge process (HDS), a relatively high investment is required in order to attain crystallised end-products. In its various manifestations, the HDS process employs a sludge recycle system during the oxidation of ferrous iron present in AMD (Zinck and Griffith, 2000; Aube and Zinck, 1999). The end-products of oxidation are a diverse and often 
poorly defined mixture of iron and non-ferrous compounds. The iron component varies from non-crystalline amorphous ferrihydrite $\mathrm{Fe}(\mathrm{OH})_{3}$ to crystallised ferric oxides such as lepidocrocite $(\gamma$-FeOOH$)$. The crystallinity and density of the end-products are in direct proportion to the investment in reactors (multistage neutralisation), energy, chemicals (e.g. flocculating polymer, insertion of oxygen) and control technology. Non-ferrous metal ions dissolved in the AMD are either "stabilised" along with the crystallised iron oxides or precipitate as their own hydroxides (Zinck and Griffith, 2000; Aube and Zinck, 1999). However, a significant portion of the non-iron metals cannot be stably removed by the HDS method. Another noteworthy disadvantage of the HDS process is that the entire AMD volume must pass through the entire reactor system prior to sludge-effluent separation.

In recent years, an ambient temperature ferrite process has been developed for the treatment of AMD (McKinnon et al., 2000; Lahav et al., 2003; Morgan et al., 2001). The ambient temperature ferrite process approach to metals removal from AMD is centred on the iron oxide magnetite which can be formed by the partial oxidation of ferrous solutions. Magnetite has several key properties which make it an ideal end-product of oxidation for metals removal from AMD and possibly other industrial wastes: it has excellent settling properties, forms a high-density, rapidly dewatering sludge which is very stable at low $\mathrm{pH}$ values, and it has the capacity to effect non-ferrous metal removal and stabilisation via cation substitution. It can thus be used to remove all dissolved metals from the main AMD stream in a single step, at relatively short retention times. Furthermore, the magnetic sludge product may have industrial applications, e.g. use as coagulating agent in certain water treatment processes or the manufacturing of low-quality magnets.

Magnetite is a partially oxidised iron oxide with the formula $\mathrm{Fe}_{3} \mathrm{O}_{4}$ (i.e. $\mathrm{Fe}^{3+}{ }_{2} \mathrm{Fe}^{2+} \mathrm{O}_{4}$ ). It thus conforms to the general formula $\mathrm{M} 1^{3+}{ }_{2} \mathrm{M} 2{ }^{2+} \mathrm{O}_{4}$ for ferrites, where $\mathrm{M} 1$ and $\mathrm{M} 2$ stand for any of a number of possible metals. Magnetite is therefore a ferrite in which the metal component is made up purely of iron. If a solution dominated by iron but containing smaller concentrations of other metal species (such as are found in AMD) is transformed into ferrite, then the resulting precipitant will be dominated by magnetite but some of the iron atoms will be replaced by non-ferrous cations, making for "substituted magnetite" or "mixed-species" ferrites. These properties account for the metal-removing capabilities of magnetite and have been successfully deployed in a hightemperature ferrite process for the treatment of laboratory wastes (Katsura et al., 1977; Tamaura et al., 1991a, b).

The key challenges in developing an ambient temperature ferrite process for the removal of metals from AMD are threefold: To achieve ferrite formation at ambient temperature, to do so at adequate reaction and settling rates and to do so in the presence of calcium which is known to inhibit ferrite formation (Lahav et al., 2003; Wang et al., 1996).

Previous results have shown the feasibility of ambient temperature magnetite formation from ferrous solutions (1 $200 \mathrm{mg} \mathrm{Fe} / \mathrm{l}$ ) in the presence of magnetite seed (Morgan et al., 2001; Lahav et al., 2003). The presence of a threshold concentration of magnetite seed was found to channel the end-products exclusively towards magnetite formation. Under the same conditions, in the absence of seed, the end-products consisted of a mixture of iron oxides containing a maximum of $\sim 17 \%$ magnetite. These investigations delineated the effects of airflow rate, seed concentration, $\mathrm{pH}$ and temperature on magnetite formation under batch conditions. Significant findings were that oxidation is the rate-limiting step in the domain where pure magnetite is formed, and that magnetite seed concentration does not affect the rate of ferrite formation. The favourable settling properties (SVI $=8 \mathrm{ml} / \mathrm{g}$ ) and $\mathrm{pH}$ stability of the magnetite sludge were also documented (Lahav et al., 2003). Furthermore, in line with the results of others (Wang et al., 1996; Perez et al., 1998), calcium was shown to markedly inhibit magnetite formation under batch conditions (Lahav et al., 2003).

The current paper reports results for seeded ferrite formation from ferrous solutions obtained under steady-state conditions, both in the absence and presence of calcium. The previously investigated batch conditions were heterogeneous with respect to the ferrous concentration and ferrous-to-seed ratio. Since a high background ferrous concentration is known to favour magnetite formation, it is desirable to control this parameter. Thus, a reactor system was designed which enabled the ferrous concentration to be maintained at a constant value (dynamic steady-state conditions). This facilitated easy investigation into the effect of ferrous species concentration on magnetite formation and also allowed the incorporation of a "contact stabilisation" reactor used to increase the $\mathrm{Fe}^{2+}$ to $\mathrm{Ca}^{2+}$ ratio prior to oxidation. The former has led to the discovery of a critical threshold effect and together with the latter paved the way to the proposal of a technique aimed at bypassing the calcium inhibition effect. Another favourable aspect that emanates from the introduction of the "contact stabilisation" reactor is a significant reduction in the size of the oxidation reactor necessary, because only the sludge is subjected to oxidation rather than the bulk AMD flow.

\section{Materials and methods}

\section{Experimental set-up}

Figures 1 and 2 show the two reactor configurations investigated. Figure 1 shows the configuration used for ferrite formation in the absence of calcium. Magnetite seed is recycled from the settling tank to the main oxidising reactor so as to maintain the total iron concentration in it at approximately $20.0 \mathrm{~g} \mathrm{Fe} / \mathrm{l}$. A ferrous solution representing the $\mathrm{AMD}$ is introduced into the main oxidising reactor, which is maintained at $\mathrm{pH}$ 10.5. The introduction of air causes oxidation of ferrous to ferric in the main reactor allowing for magnetite formation. The fraction of iron in the main oxidising reactor which has not yet transformed into magnetite was maintained at a constant concentration (50 to 100,150 to 250 and $\sim 500 \mathrm{mg} \mathrm{Fe} / \mathrm{l}$ in the three experiments). Air was introduced into the main oxidising reactor at a flow rate to maintain this iron fraction at the three selected concentrations. The effluent of the main oxidising reactor flowed into a settler where solid-liquid separation occurred. The clarified effluent from which all iron has been removed flowed out of the system. The sludge, which is a mixture of crystallised magnetite and ferrous-hydroxy species, was then returned to the main reactor via a second oxidising reactor designed to complete the oxidation process. The $\mathrm{pH}$ of this reactor was also maintained at 10.5. Both oxidation reactors (5.2 and $2.5 \mathrm{I}$ ) were constantly mixed from above by a rotating paddle.

Figure 2 shows the configuration used for magnetite formation in the presence of calcium. The seed concentration in the oxidising reactor was again maintained at $\sim 20.0 \mathrm{~g} \mathrm{Fe} / \mathrm{l}$. In this case, however, separate equimolar ferrous and calcium solutions, representing the AMD and added lime, were first introduced into a pH 10.5 "contact stabilisation" reactor. The effluent of this reactor flowed into the settler. The clarified effluent left the system while part of the sludge was pumped to the oxidising reactor. The ferrous iron in the underflow was therefore significantly concentrated relative to the concentration in the source AMD whilst the calcium concentration remained virtually unchanged. 


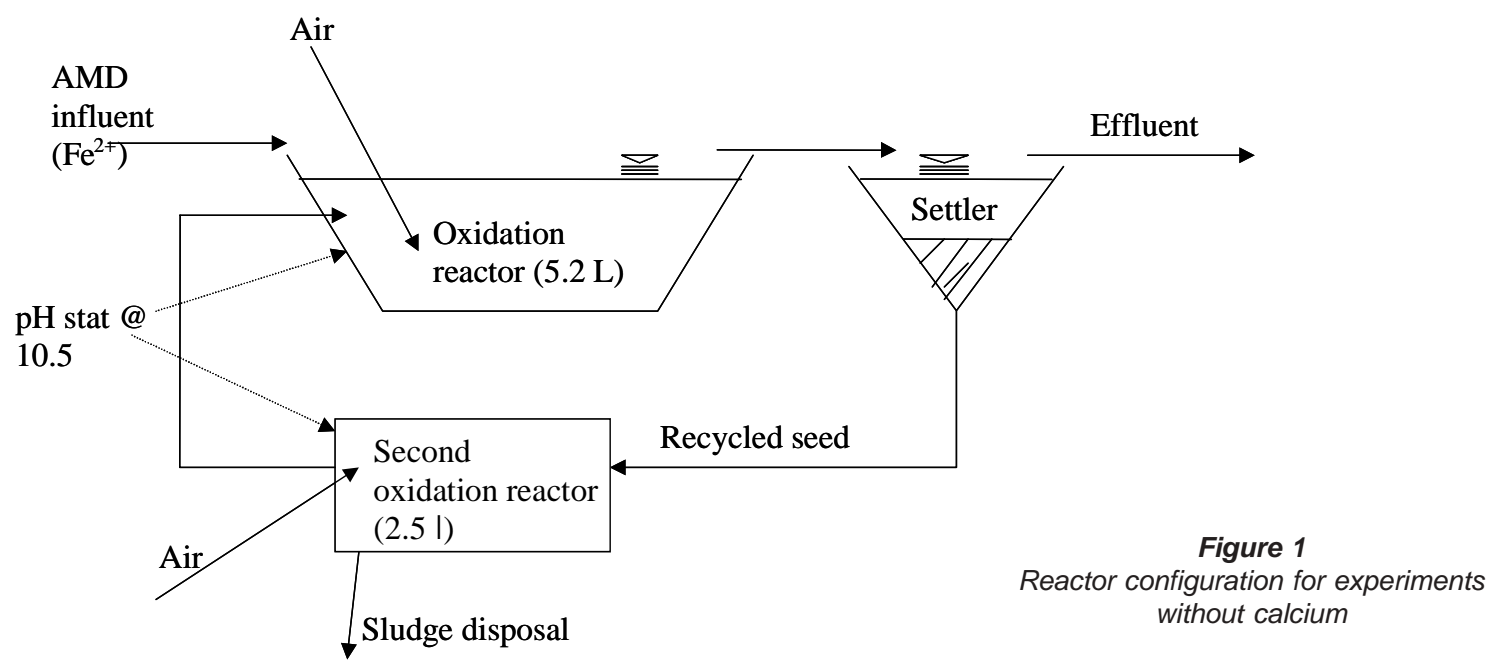

\section{Reagents}

The following analytical grade reagents were used as received: $\mathrm{FeSO}_{4} \cdot 7 \mathrm{H}_{2} \mathrm{O}, \mathrm{Na}_{2} \mathrm{SO}_{4}, \mathrm{NaOH}, \mathrm{CaCl}_{2}, 32 \% \mathrm{HCl}, 1,10$-phenanthroline monohydrate, glacial acetic acid, $\mathrm{NH}_{4} \mathrm{C}_{2} \mathrm{H}_{3} \mathrm{O}_{2}$.

\section{Experimental procedure and analysis}

In all experiments, both reactors were mixed at $200 \mathrm{r} / \mathrm{min}$ and completely mixed conditions were attained. Ferrous load was approximately $11.5 \mathrm{mg} \mathrm{Fe} / \mathrm{l} \cdot \mathrm{min}$. Temperature was $22 \pm 2^{\circ} \mathrm{C}$ at all times. Dissolved oxygen concentration was continuously measured in both oxidation reactors using a YSI oxygen meter. Magnetite used for the initial start-up seed was made under ambient temperature conditions described by Morgan et al. (2001). A solution of $0.359 \mathrm{M}$ ferrous sulphate and $0.359 \mathrm{M}$ sodium sulphate (to establish an $\mathrm{SO}_{4}{ }^{2-}: \mathrm{Fe}^{2+}$ ratio of 2:1) served to simulate the AMD water. The general procedure for an experiment was as follows: The AMD solution was continuously pumped into the reactor system in parallel with either tap water (experiments without calcium) or a $0.359 \mathrm{M}$ calcium chloride solution (experiments with calcium) at a steady rate. Sludge was wasted from the system at frequent regular intervals so as to maintain the seed concentration in the main oxidising reactor at approximately $20 \mathrm{~g} \mathrm{Fe} / \mathrm{l}$. Air was introduced into the main oxidising reactor at a constant flow rate of $0.06 \mathrm{l} / \mathrm{min}$. In the case where calcium was absent, air was introduced into the secondary oxidising reactor at a rate sufficient to keep the ironintermediate concentration at the pre-selected concentration. The $\mathrm{pH}$ was maintained at 10.5 in each reactor by the automatic addition of a $1 \mathrm{M} \mathrm{NaOH}$ solution. The term "iron-intermediate" referred to in this paper represents all ferrous and/or ferric species which dissolve within $1 \mathrm{~min}$ at $\mathrm{pH} 2$ (i.e. an iron-intermediate which has not yet been transformed into relatively insoluble end-products of oxidation such as magnetite or goethite).

The $\mathrm{pH}$, dissolved oxygen, "iron-intermediates" and total iron were measured in each compartment at various times. The term "total iron" represents the iron in a sample which undergoes complete dissolution in $32 \% \mathrm{HCl}$ (this can include "iron-intermediates" and/or magnetite seed and/or other end-products of oxidation).

The system was run continuously for at least three sludge ages. Characterisation of the sludge was performed using two qualitative (XRD and Mössbauer) and one quantitative method (ferrous to total iron ratio):

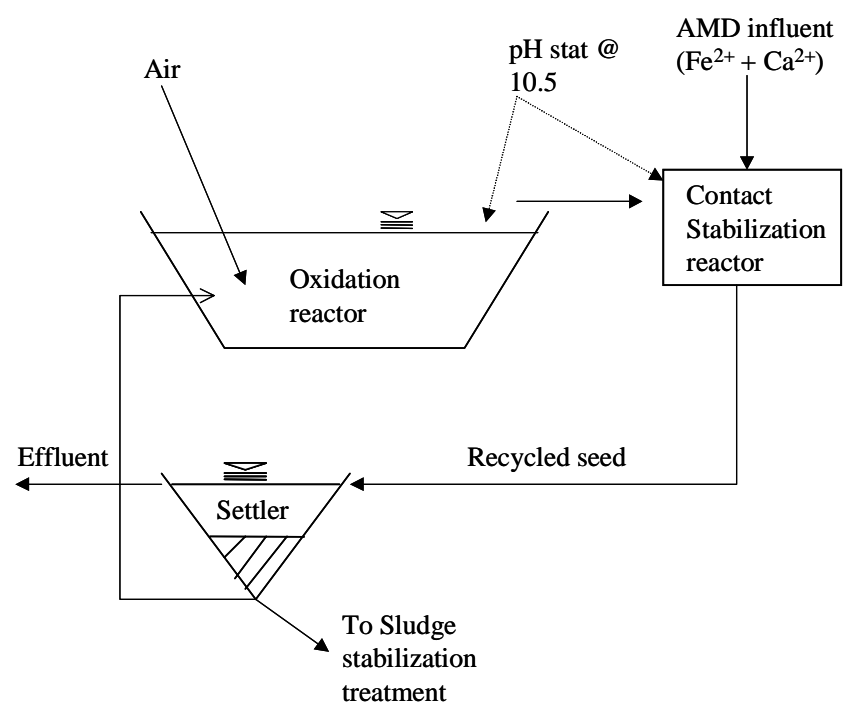

Figure 2

Reactor configuration used in experiments with calcium (dimension of reactors as in Fig. 1)

X Ray diffraction was performed using a Phillips PW3710 XR diffractometer with a normal four copper tube.

${ }^{57} \mathrm{Fe}$ Mössbauer spectroscopy: Measurements were performed in conventional transmission geometry. A linear motor driven by a triangular reference wave-form was used to scan the resonance profile. A $\mathrm{Kr}-\mathrm{CO}_{2}$ proportional counter was used to detect the transmitted $14.4 \mathrm{keV}$ resonance radiation from a $10 \mathrm{mCi}{ }^{57} \mathrm{Co}(\mathrm{Rh})$ radioactive source. Each dried powdered sample was mounted in a specially designed powder-clamp holder. Sample quantities were thoroughly mixed with an inorganic buffer material and the mixture of sample and buffer distributed in the sample holder to form a disk of uniform thickness of 20 to $25 \mathrm{mg} / \mathrm{cm}^{2}$ for transmission Mössbauer measurements. Data acquisition of each spectrum and its mirrorimage was for a duration to ensure at least $\sim 100000$ counts in each of 1024 channels of a PCA-based multichannel analyser. Prior to analysis each spectrum was folded with its mirror image and adjacent channels subsequently added. This serves to remove geometrical base-line distortions and reduces the $(\sqrt{ } \mathrm{N})$ statistical scatter in the final data set used for analysis. The fitting program NORMOS (distributed by WISSEL-Germany) has been used for 


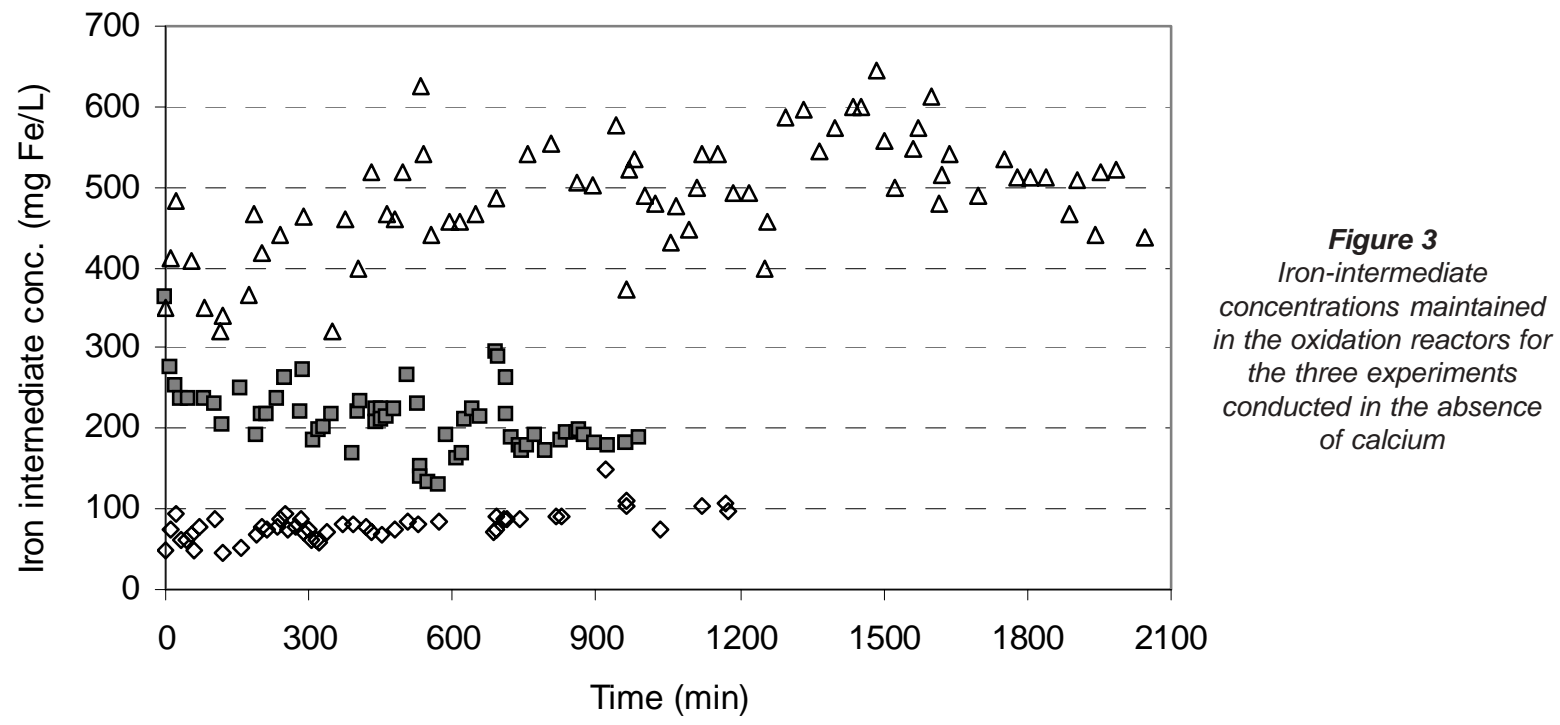

$\diamond$ Experiment 1 口 Experiment $2 \Delta$ Experiment 3

theoretical fits of the data with Lorentzian line-shapes to deconvolute various sub-components (phases) in the spectrum. A minimum number of subspectra (doublets, sextets and/or distribution of sextets) are used to obtain the best fit to the total spectrum.

Determination of $\mathrm{Fe}^{2+} / \mathrm{Fe}_{T}$ ratio in sludge: Two $1 \mathrm{ml}$ samples taken from high and middle zones of the mixed reactor were dissolved in $4 \mathrm{ml}$ of $32 \% \mathrm{HCl}$. Complete dissolution takes about 15 min. The samples were further diluted with distilled water to a concentration and $\mathrm{pH}$ value suitable for total iron and ferrous measurements. Ferrous iron was measured by the phenanthroline method. Total iron was measured using a bench-top Spectroquant (Merck) system. SVI was determined according to the method given in Standard Methods, 1998. Leach tests involved mixing a sludge sample and allowing it to settle in $500 \mathrm{ml}$ of a $0.01 \mathrm{M}$ aqueous $\mathrm{HCl}$ solution (i.e. $\mathrm{pH}$ 2). Thereafter, samples of the supernatant were taken at intervals and measured for total iron. At the end of the test, the entire mixture was filtered and the solids were dissolved in $32 \% \mathrm{HCl}$ in order to determine the sample mass (as $\mathrm{Fe})$. Results were then expressed as $\%$ mass loss.

\section{Results and discussion}

\section{Formation of magnetite at steady-state in the absence of calcium: Effect of the iron-intermediate concentration}

The reactor system used for these experiments is shown in Fig. 1. Figure 3 shows the iron-intermediate concentration maintained in the oxidising reactors for three different experiments (Experiments 1,2 , and 3 corresponding to 50 to 100,150 to $250, \sim 500 \mathrm{mg} \mathrm{Fe} / \mathrm{l}$, respectively).

\section{End-product analysis}

When the process was operated with an iron-intermediate concentration of 50 to $100 \mathrm{mg} \mathrm{Fe} / \mathrm{l}$ the colour of the precipitate produced was green-brown. The colour of magnetite is charcoal. It was therefore apparent that under these conditions pure magnetite was not being produced.

Figure 4a shows the Mössbauer spectrum (MS) for the precipitate formed at an iron-intermediate concentration in the range
50 to $100 \mathrm{mg}$ Fe/l. The spectrum is fitted with three components, two of which are crystalline component sextets representing the Asite and B-site in the magnetite fraction of the sample (compare dashed lines in Fig. 4a with Fig. 4c). The third component is modelled as an additional distribution of magnetic fields with Mössbauer parameters typical of poorly crystalline goethite $(\alpha-\mathrm{FeOOH})$ (thin solid line) (Pollard et al., 1992). Therefore the Mössbauer analysis suggests the presence of two Fe-bearing phases, viz. magnetite and goethite. The integrated area under each subspectrum in the Mössbauer analysis makes it possible to ascribe $44 \%$ of the iron in the sample to goethite and $56 \%$ to magnetite. Chemical analysis of this sample gave a ferrous fraction of $13 \% \pm$ $1 \%$ (as compared to $\sim 33 \%$ in pure stoichiometric magnetite). The relative areas of the A-site and $\mathrm{B}$-site sextets permit a quantification of the degree of oxidation of the magnetite fraction from the Mössbauer spectrum (Vandenberghe et al., 1990). The Mössbauer spectral analysis also indicates that $14 \%$ of the total iron in the sample was in the ferrous form.

For further assessment, a sample of the same precipitate was dissolved in $32 \% \mathrm{HCl}$ which dissolves all the magnetite within 15 min, leaving a yellow-brown residual suspended solid which was analysed by Mössbauer spectroscopy and XRD. Figure 4b shows the MS spectrum for this sample. The overall fit to the spectrum is the solid line through the data points represented as open circles. A dashed line representing a distribution of magnetic fields supposed to be indicative of the poorly crystalline bulk goethite phase is discerned, similar to that seen in Fig. 4a. In addition, a central doublet attributed to (superparamagnetic) nanocrystalline goethite is also present. This component likely arises from the effects of the concentrated $\mathrm{HCl}$ on the goethite fraction. The XRD results for this sample are shown in Fig. 5 and have signatures of crystalline goethite, with no evidence of other iron oxides or oxy-hydroxides. Taken together, these results confirm that the precipitate was not purely magnetite, but that large amounts of another Fe-bearing phase, goethite, were present.

At an iron-intermediate concentration of 150 to $250 \mathrm{mg} \mathrm{Fe} / \mathrm{l}$ the colour of the precipitate was green-brown as in the previous experiment, indicating the presence of products of oxidation other than magnetite. Detailed characterisation of this precipitate was not pursued. 
At an iron-intermediate concentration of $\sim 500 \mathrm{mg} F / / \mathrm{l}$ the precipitate, attained after dynamic steady state had been reached, was charcoal in colour. Figure 6 shows the XRD pattern for this precipitate compared to the reference pattern for stoichiometric magnetite. The pattern is characteristic of magnetite and there is no evidence of non-magnetite phases. The percentage ferrous content for this sample was $28 \% \pm 1 \%$ from the chemical analysis.

Based on the sludge analysis it was therefore apparent that there is a critical threshold for the iron-intermediate concentration in order to form substantially pure magnetite. Results of sludge analysis indicated a steady-state iron-intermediate concentration of approximately $500 \mathrm{mg}$ Fe/l above which solely magnetite was produced. Below this threshold, goethite was found to be the main end-product of oxidation. This result is in accord with the literature on magnetite formation in the absence of seed. In the literature it is qualitatively stated that a high ferrous concentration favours magnetite as the end-product of the oxidation of ferrous solutions (Cornell and Schwertmann, 1996).

\section{Formation of magnetite at steady-state in the presence of calcium: Effect of $\mathrm{Fe}^{2+}$ to $\mathrm{Ca}^{2+}$ ratio}

Figure 2 shows the reactor system used for experiments in which calcium was present. It has been previously suggested (Perez et al., 1998) that the mechanism of calcium interference upon ferrite formation is via its incorporation into the ferrite crystal lattice. The larger ionic diameter of calcium is postulated to distort the lattice structure and thereby disrupt ferrite formation. It was thus postulated that increasing the iron-intermediate to calcium ratio in the oxidation reactor would favour ferrous rather than calcium incorporation into the lattice, thereby reducing the inhibitory calcium affect.

Figure 7 shows the iron-intermediate concentration in the oxidising reactor for two such experiments. In the absence of calcium a concentration of $>500 \mathrm{mg}$ Fe/l was found necessary for magnetite formation. An experiment with calcium was therefore performed just above this threshold concentration (i.e. in the range 500 to $800 \mathrm{mg} \mathrm{Fe} / \mathrm{l})$. In this experiment the ferrous fraction in the sludge was found to be only $18 \% \pm 1 \%$ by chemical analysis. Mössbauer and XRD results for this experiment are shown in Fig. 8. Although features indicative of magnetite are dominant in both measurements, both modalities also show clear evidence of an additional non-magnetite component in the sample. Mössbauer analysis reveals that this is an additional purely ferric component (solid line subspectrum in Fig. 8) accounting for $~ 20 \%$ of the total iron in the sample. The derived Mössbauer parameters for this component are not typical of goethite, and this component therefore represents one or more unidentified ferric species. MS analysis indicates that the percentage ferrous content of the magnetite phase is $25 \%$. This amounts to a net ferrous fraction of $20 \%$ of the total iron in the sample, which accords well with the $18 \% \pm 1 \%$ obtained from the chemical analysis.

Raising the iron-intermediate concentration to between 1200 and $1700 \mathrm{mg} \mathrm{Fe} / \mathrm{l}$ (Fig. 7) resulted in a sludge consisting of predominantly (>95\%) magnetite with a ferrous fraction of $30 \% \pm$ $1 \%$ by chemical analysis, and $27 \% \pm 1 \%$ by Mössbauer analysis. This finding was further substantiated by XRD analysis. Mössbauer and XRD results for this experiment are shown in Fig. 9.

The results presented in this section appear to link the inhibitory effect of calcium on magnetite formation to the iron-intermediate to $\mathrm{Ca}^{2+}$ ratio. It was postulated before that an increase in this ratio might serve to overcome this inhibition. It has indeed been found that at the higher iron-intermediate concentrations (accom-
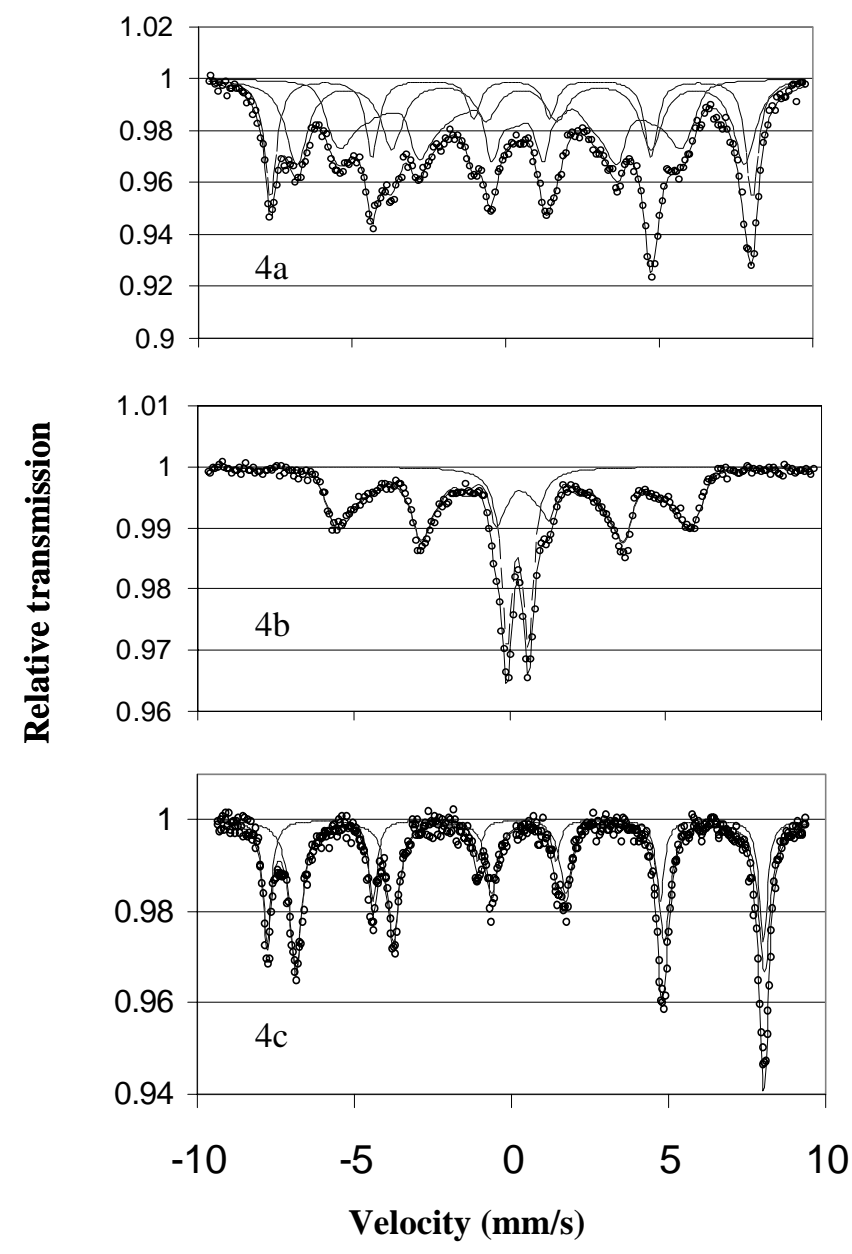

Figure 4

a. Mössbauer spectrum for the precipitate from the experiment depicted in Fig 1. See text for details;

b. Mössbauer spectrum for the precipitate from the experiment depicted in Fig. 1 after treatment with $32 \% \mathrm{HCl}$;

c. Mössbauer spectrum for a sample of near-stoichiometric magnetite which serves as a standard of reference. In all cases open circles represent the raw data, with overall theoretical fit as a solid line through the data points

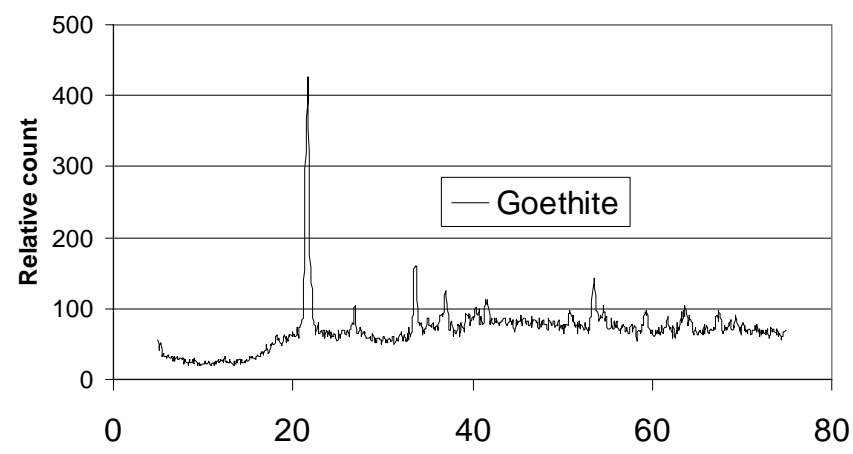

2 Theta (degrees)

Figure 5

$X R D$ pattern for the precipitate from Experiment 1 (ironintermediate concentration $=50-100 \mathrm{mg}-\mathrm{Fe} / \mathrm{l})$ after treatment with $32 \% \mathrm{HCl}$ 

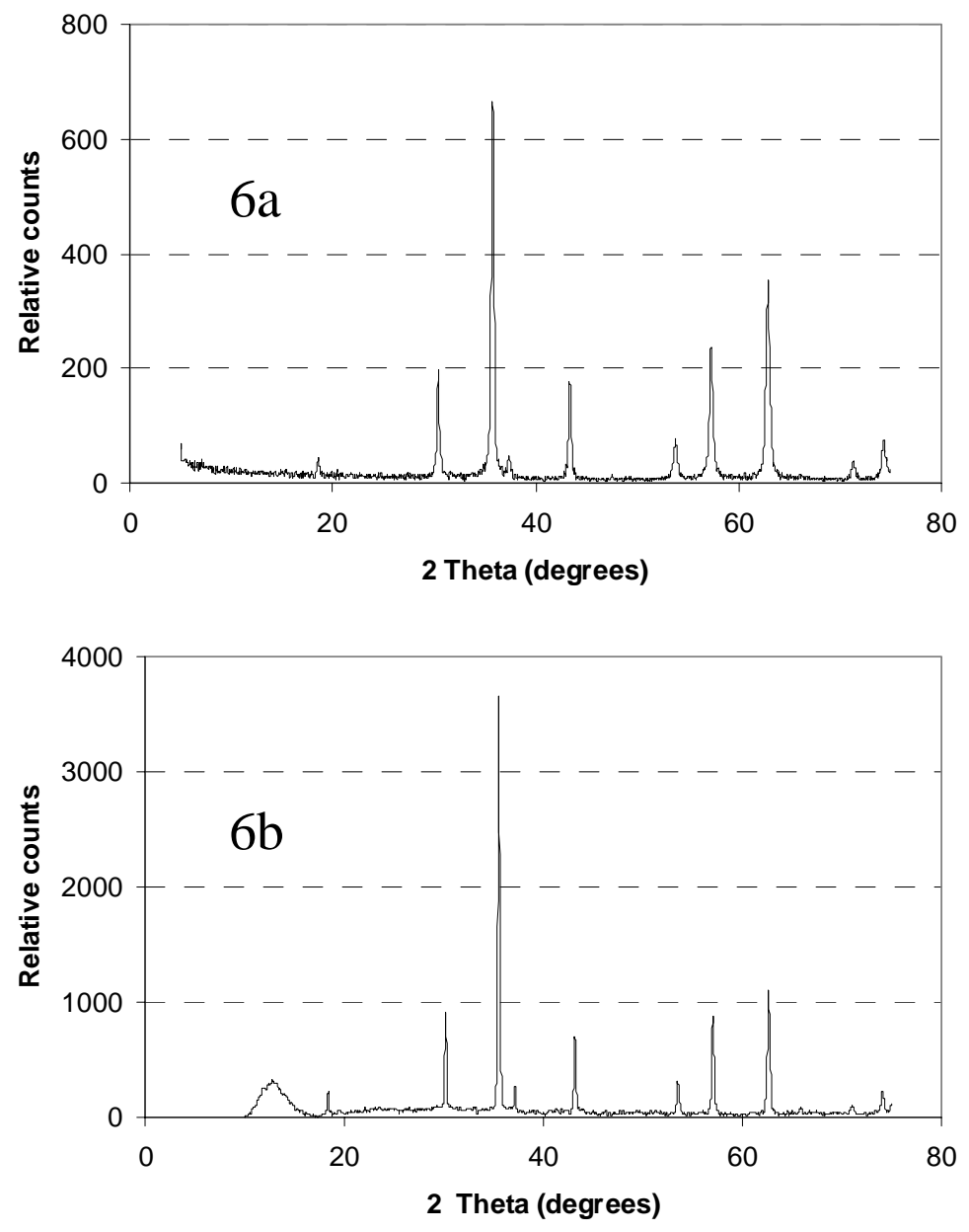

Figure 6

a. XRD pattern for the precipitate from the experiment where the ironintermediate concentration was maintained at $\sim 500 \mathrm{mg} F e / l$.

b. XRD pattern for a reference sample of magnetite (the same sample used for the MS analysis shown in Fig. 4c).

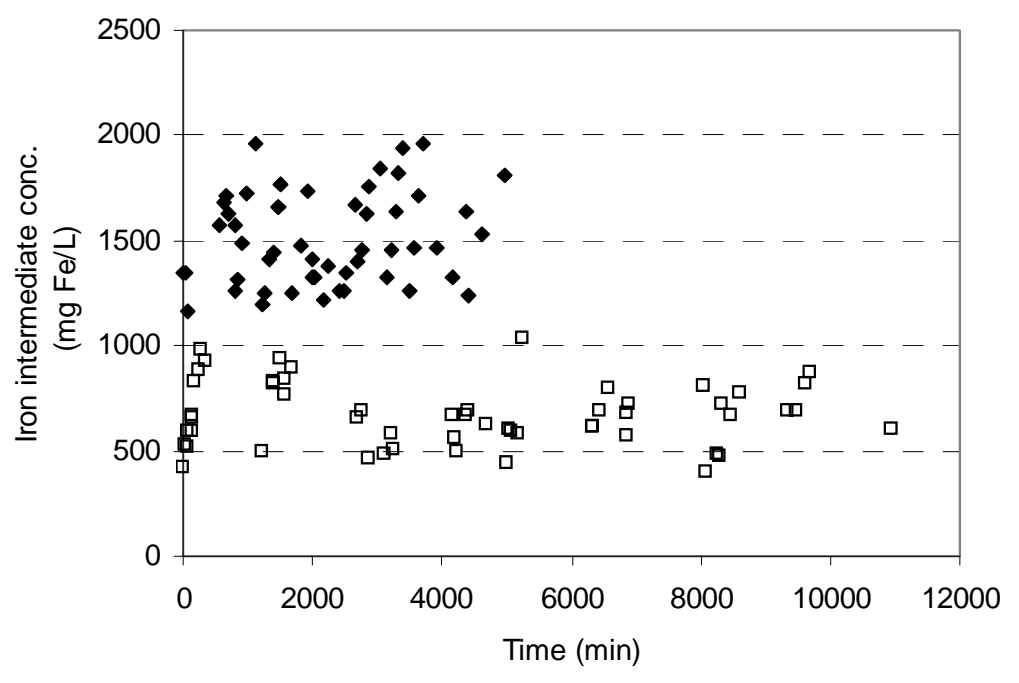

- Experiment 2 a Experiment 1

Figure 7

Iron-intermediate concentrations maintained in the oxidation reactors for the two experiments conducted in the presence of calcium panied by a constant dissolved calcium concentration) substantially pure magnetite was produced in conjunction with less than $5 \%$ of other iron phases.

It is noted that in the case where magnetite was formed in the presence of calcium, the sludge wasted from the main oxidising reactor contained 1200 to $1700 \mathrm{mg}-\mathrm{Fe} / \mathrm{l}$ of iron-intermediate. As in the case where calcium was not present, this sludge can be further concentrated in a settling tank (which amplifies the iron-intermediate concentration and further increases the Fe to Ca ratio). To complete the process, this concentrated sludge should be subjected to exhaustive oxidation, preferably under batch conditions as described in a previous paper (Lahav et al., 2003).

\section{The role of the contact stabilisation reactor}

As suggested above, enhancing the iron-intermediate to $\mathrm{Ca}$ ratio appears to overcome the inhibitory affect of calcium on magnetite formation. This was achieved by placing a contact stabilisation (CS) reactor before the settler. The $\mathrm{pH}$ of the $\mathrm{CS}$ reactor was maintained at 10.5 , as in the oxidation reactor. The dissolved iron present in the raw AMD introduced into the CS reactor thus fully precipitates (as a ferrous hydroxy species) and is subsequently adsorbed onto the magnetite seed. The near-instantaneous time ( $\mathrm{min}$ ) required for these steps allows for a relatively small CS reactor. The effluent from the CS reactor containing magnetite seed coated with ferrous hydroxy species then reaches the settler. The seed particles greatly enhance the settling of the ferrous hydroxy phase which would otherwise, in the absence of seed, form a bulky voluminous floc with poor settling properties. This results in both a concentrated sludge and a short retention time in the settler. The concentration of the ferrous hydroxy species in the underflow sludge of the settler is enhanced 3 to 5 times relative to the concentration of dissolved iron in the raw AMD. Observing no gypsum crystals in the underflow from the settler (although some gypsum growth was observed on the walls of the settler), the concentration of calcium in the main oxidising reactor would not have increased. Consequently, the $\mathrm{Fe}$ : Ca ratio would be elevated by at least the solid-liquid separation factor. Since $\mathrm{Fe}^{2+}$ and $\mathrm{Ca}^{2+}$ in the influent were introduced at equimolar concentrations, it would appear that increasing the ratio between the iron-intermediate and the calcium to above 3 has the effect of largely overcoming the calcium inhibition effects.

Another notable affect of the CS and settler sequence configuration (see Fig. 2) is the separation of the metals from the bulk AMD volume prior to oxidation. This means that the bulk AMD volume does not enter the oxidation reactor, allowing for much smaller infrastructure costs.

\section{Effluent and sludge characteristics}

Under the experimental conditions shown in Fig. 7 (iron-intermediate concentration $=1200$ to $1700 \mathrm{mg}$ Fe/l, calcium present), the total iron concentration in the effluent leaving the settling tank was always less 
than $1.0 \mathrm{mg} / \mathrm{l}$ and the final sludge, composed of essentially pure magnetite, settled exceptionally well $(\mathrm{SVI}=3.2 \mathrm{ml} / \mathrm{g}$ ). After standing for $14 \mathrm{~d}$, the wasted sludge attained a paste-like consistency with a concentration of $257 \mathrm{~g} \mathrm{Fe} / \mathrm{l}$. An indication of the stability of the sludge at $\mathrm{pH} 2$ is demonstrated by the data shown in Fig. 10. After an initially rapid increase the mass loss began to plateau at $15.6 \%$ after $77 \mathrm{~d}$. Such a limited release of ferrous iron is a documented property of magnetite in acidic aqueous solution (Jolivet and Tronc, 1988).

\section{Summary and conclusions}

- The conditions under which magnetite can be produced from simulated AMD in a continuously operated ambient temperature ferrite process, both in the absence and presence of calcium, are described. The presence of calcium simulates the use of lime as a pH-elevating agent. The dynamic steady-state conditions required can be easily attained using relatively unsophisticated equipment and methods.

- Experiments without calcium reveal a threshold iron-intermediate concentration of approximately $500 \mathrm{mg} \mathrm{Fe} / \mathrm{l}$ above which solely magnetite is formed. Below this concentration, goethite $(\alpha-\mathrm{FeOOH})$ was formed in significant amounts.

- Experiments in the presence of calcium revealed the formation of substantially pure near-stoichiometric magnetite at relatively higher (1 200 to $1700 \mathrm{mg}$ Fe/l) iron-intermediate concentrations. Such concentrations can be attained and maintained by the introduction of a contactstabilisation/settler sequence before the main oxidising reactor. The elevation of the iron-intermediate concentration in the oxidising reactor together with the incorporation of a contactstabilisation/settler sequence increases the $\mathrm{Fe}: \mathrm{Ca}$ ratio in the oxidation reactor by 3 to 5 times. It is proposed that this is the mechanism whereby the inhibitory effect of calcium on magnetite formation is overcome. A diminution in the purity of the magnetite end-product of oxidation was observed at lower iron-intermediate concentrations (representing lower iron-intermediate to calcium ratios).

- In all experiments, the iron concentration in the effluent leaving the settling tank was lower than $1 \mathrm{mg} \mathrm{Fe} / \mathrm{l}$ and the final sludge, when composed of essentially pure magnetite, settled extremely well $(\mathrm{SVI}=3.2 \mathrm{ml} / \mathrm{g})$.

- The proposed reactor design results in early separation of a metals-containing stream from the bulk AMD volume, resulting in smaller reactor infrastructure needs.

- Results indicative of the favourable stability properties of the sludge have also been presented. These compare favourably with those of the HDS process.

- The concept has potential to be flexibly applied to non-AMD waste streams containing dissolved metals.
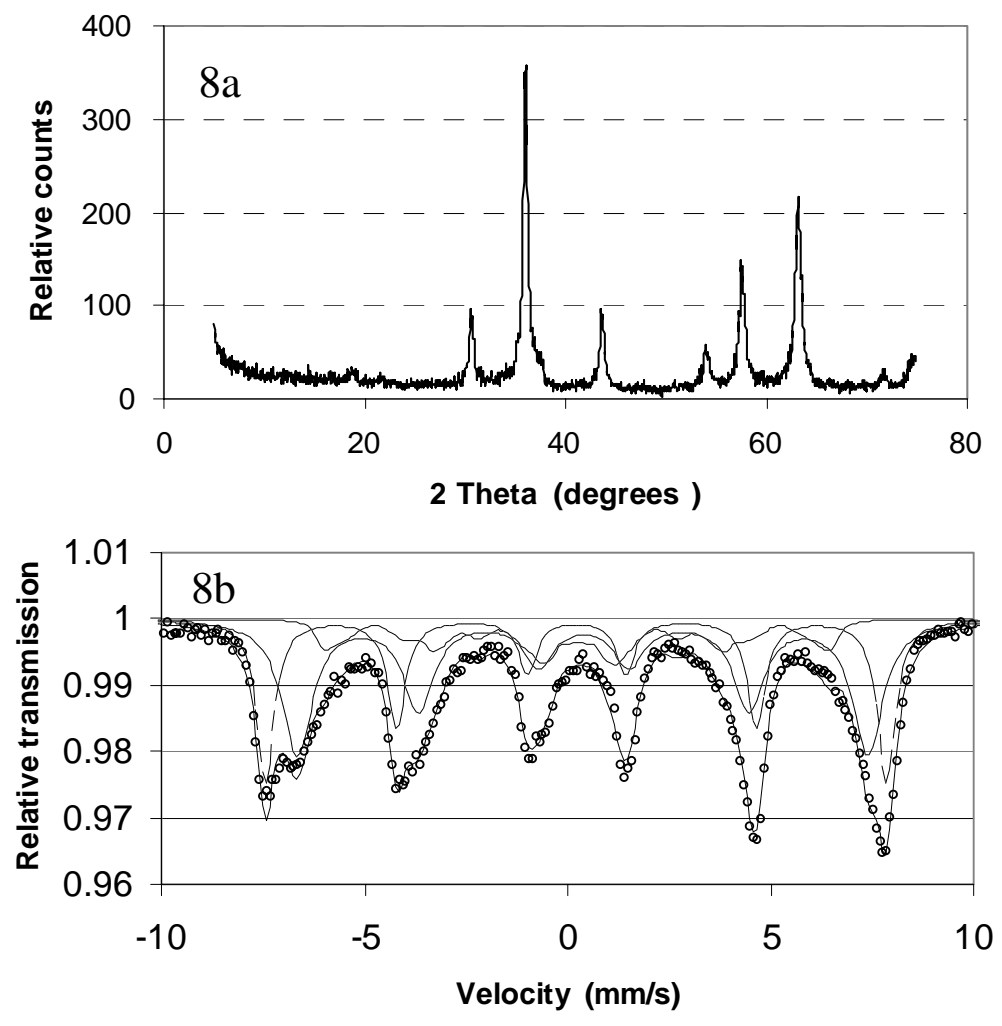

Figure 8

$X R D(8 a)$ and $M S(8 b)$ for sludge from experiments conducted in the presence of calcium (iron-intermediate concentration of $500-800 \mathrm{mg} \mathrm{Fe} / \mathrm{l}$ )
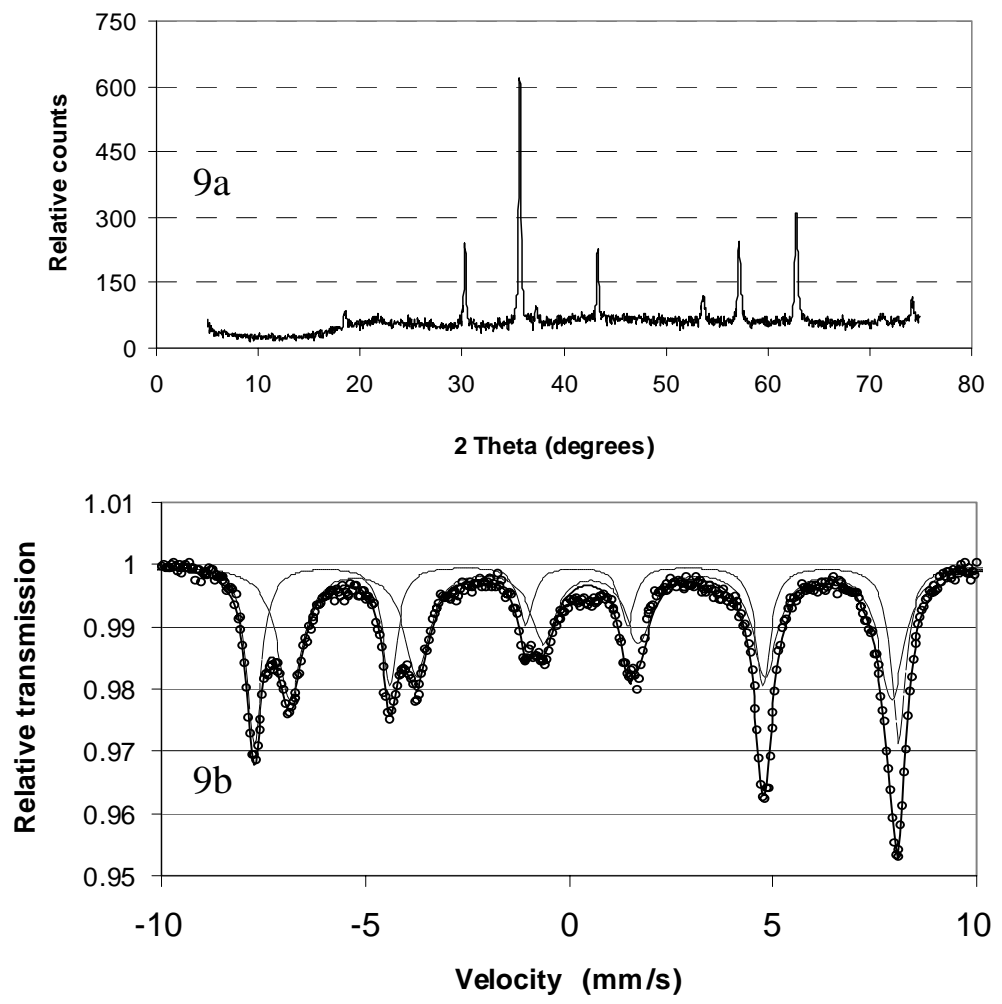

Figure 9

$X R D$ (9a) and MS (9b) for sludge from experiments conducted in the presence of calcium (iron- intermediate concentration of 1200 to $1700 \mathrm{mg} \mathrm{Fe} / \mathrm{l})$ 


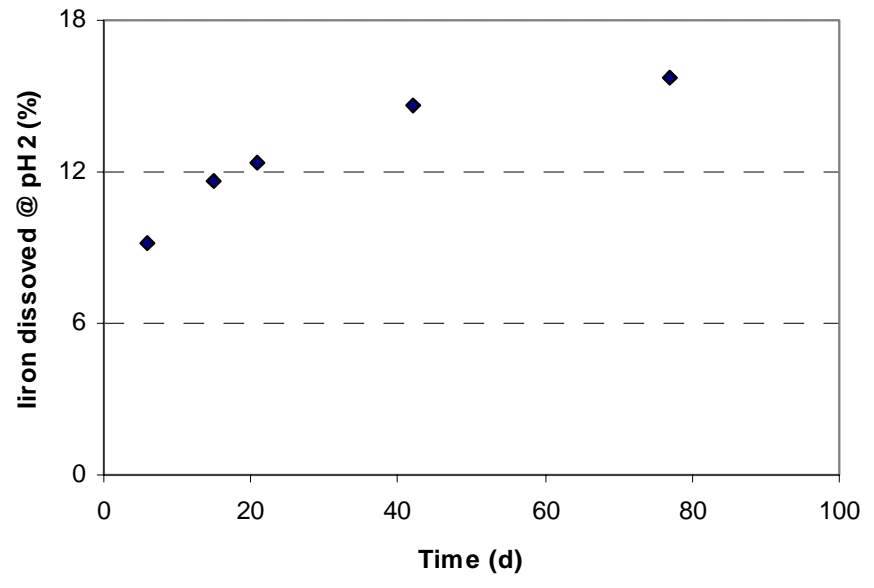

Figure 10

Results of a $\mathrm{pH} 2$ leach-test conducted with sludge derived from the experiment with calcium (iron-intermediate concentration $=1200$ to $1700 \mathrm{mg} \mathrm{Fe} / \mathrm{l})$

\section{Acknowledgements}

The Water Research Commission of South Africa is thanked for its financial support of this project.

\section{References}

AUBE BC and ZINCK JM (1999) Proceedings for Sudbury '99, Mining and Environment II, Ontario, Canada, September. 261-270.

BLESA MA and MATIJEVIC E (1989) Phase transformations of iron oxides, oxo-hydroxydes, and hydrous oxides in aqueous media. $A d v$. in Colloid and Interface Sci. 29 173-221.

CORNELL RM and SCHWERTMANN U (1996) The Iron Oxides: Structure, Properties, Reactions, Occurrence and Uses. VCH, Weinheim, Germany.
JOLIVET J and TRONC E (1988) Interfacial electron transfer in colloidal spinel iron oxide. Conversion of $\mathrm{Fe}_{3} \mathrm{O}_{4}-\mathrm{gFe}_{2} \mathrm{O}_{3}$ in aqueous medium. $J$. of Colloid and Interface Sci. 125 (2) 688-700.

KATSURA T, TAMAURA Y and TERADA H (1977) Treatment of the laboratory wastewaters by the magnetic separation process. Indust. Water 233 16-21.

LAHAV O, MORGAN BE, HEARNE G and LOEWENTHAL RE (2003) One-step ambient temperature ferrite process for treatment of acid mine drainage waters. J. of Environ. Eng. 129 (2) 155-161.

McKINNON W, CHOUNG JW, XU Z and FINCH JA (2000) Magnetic seed in ambient temperature ferrite process applied to acid mine drainage treatment. Environ. Sci. Technol. 34 2676-2581.

MORGAN BE, LOEWENTHAL RE and LAHAV O (2001) Fundamental study of a one-step ambient temperature ferrite process for treatment of acid mine drainage waters. Water SA 27 (2) 277-282.

PEREZ OP, UMETSU Y and SASAKI H (1998) Precipitation and densification of magnetic iron compounds from aqueous solutions at room temperature. Hydrometallurgy 50 223-242.

POLLARD RJ, CARDILE CM, LEWIS DG and BROWN LJ (1992) Characterization of iron oxyhydroxide polymorphs and ferrihydrate using low-temperature, applied-field, Mossbauer spectroscopy. Clay Miner. 27 (1) 57-71.

STANDARD METHODS (1998) Methods for the Examination of Water and Wastewater $\left(20^{\text {th }}\right.$ edn.), APHA.

TAMAURA Y, TU PQ, ROJARAYANONT S and ABE H (1991a) Stabilization of hazardous materials into ferrites. Water Sci. Technol. 23 399-404.

TAMAURA Y, KATSURA T, ROJARAYANONT S and ABE H (1991b) Ferrite process: Heavy metal ion treatment system. Water Sci. Technol. 23 1893-1909.

VANDENBERGHE RE, DEGRAVE E, LANDUYT C and BOWEN LH (1990) Some aspects concerning the characterisation of iron oxides and hydroxides in soils and clays. Hyperfine Interactions 53 175-196.

WANG W, XU Z and FINCH J (1996) Fundamental study of an ambient temperature ferrite process in the treatment of acid mine drainage. Environ. Sci. Technol. 30 2604-2608.

ZINCK JM and GRIFFITH WF (2000) Proc. 5th Int. Conf. on Acid Rock Drainage, May 21-24, Denver, Colorado, Vol. 2 1027-1034. Society for Mining, Metallurgy and Exploration, Inc. 